\title{
Chapter 5 \\ Physiological Verification of the Effect of Potassium Supply on the Reduction of Radiocesium Content in Rice Grain
}

\author{
Natsuko I. Kobayashi
}

\begin{abstract}
To achieve the reduction of the radiocesium content in rice grain, the application of potassium $(\mathrm{K})$ fertilizer to the paddy field is currently recommended. However, physiological basis of the effect of the $\mathrm{K}$ addition on the radiocesium accumulation in rice has not been enough provided. Here, the uptake and the distribution of cesium (Cs) in rice plant grown in either K-deficient or $\mathrm{K}$-sufficient hydroponic medium containing ${ }^{137} \mathrm{Cs}$ are presented aiming to describe the exact impact of $\mathrm{K}$ fertilization on the $\mathrm{Cs}$ behavior within the plant. In the $\mathrm{K}$-deficient plant, the amount of ${ }^{137} \mathrm{Cs}$ accumulated in the rice grain was 10 times as much as the K-sufficient rice. The determination of ${ }^{137} \mathrm{Cs}$ content as well as other cationic ions in each part of the rice showed the intensive transport of ${ }^{137} \mathrm{Cs}$ to the ear part composed of brown rice, husk and culm, in which $\mathrm{K}$ was also accumulated. It could supposed that $\mathrm{Cs}$ transport is regulated basically similarly to the $\mathrm{K}$ transport within the plant body. Then, $\mathrm{K}$ fertilization is suggested to reduce the Cs content in rice grain efficiently through the reduction of $\mathrm{Cs}$ uptake in the roots and $\mathrm{Cs}$ accumulation to the ear part.
\end{abstract}

Keywords Oryza sativa $\bullet$ Paddy field $\bullet$ Potassium fertilization • Tracer • Uptake • Transport

\subsection{Introduction}

Among agricultural products, rice contaminated with radiocesium has received particular attention because it is the staple food of Japan and the main agriproduct in Fukushima. After 2011, an extensive survey on rice was conducted and the result showed a clear inverse relationship between soil potassium $(\mathrm{K})$ and radiocesium concentrations (http://www.maff.go.jp/j/kanbo/joho/saigai/pdf/kome.pdf). In addition, when the $\mathrm{K}$ fertilizer was applied to paddy fields where rice containing

N.I. Kobayashi $(\bowtie)$

Graduate School of Agricultural and Life Sciences, The University of Tokyo, 1-1-1 Yayoi,

Bunkyo-ku, Tokyo 113-8657, Japan

e-mail: anikoba@mail.ecc.u-tokyo.ac.jp

(C) The Author(s) 2016

T.M. Nakanishi, K. Tanoi (eds.), Agricultural Implications of the Fukushima

Nuclear Accident, DOI 10.1007/978-4-431-55828-6_5 
relatively high amounts of radiocesium was produced, the brown rice produced the following year had much lower radiocesium concentrations. Actually, many previous physiological experiments have indicated that high $\mathrm{K}$ concentration in the rhizosphere could reduce Cs absorption by the roots in several plant species (Zhi et al. 2002; Robison et al. 2009). This reduction was thought to be due to the similar chemical properties of $\mathrm{K}$ and Cs. Because they are both alkali metals, $\mathrm{Cs}$ is assumed to enter the root cells through the $\mathrm{K}$ transport apparatus, which is where the competition between these elements is thought to occur.

The competition between $\mathrm{K}$ uptake and Cs uptake in rice roots is recently described (Kobayashi et al. 2015). The kinetics of K uptake was directly analyzed

using ${ }^{42} \mathrm{~K}$, and simultaneously, the uptake rate of Cs was calculated using ${ }^{137} \mathrm{Cs}$. As the $\mathrm{K}$ concentration in the uptake medium increased, the $\mathrm{K}$ uptake rate increased and the Cs uptake rate decreased (Kobayashi et al. 2015). In Arabidopsis plants, the molecule mediating K and Cs uptake has been identified (Qi et al. 2008).

In addition to the relationship between soil $\mathrm{K}$ concentration and radiocesium contamination of rice, an intriguing observation about radiocesium distribution in rice plants was found in 2011. In some paddy fields in Fukushima, brown rice containing over $500 \mathrm{~Bq} / \mathrm{kg}$ of radiocesium was produced. We analyzed radiocesium distribution in rice seedlings harvested in those paddy fields (Paddy-field A) and found that younger organs, such as the ear and the first and second internodes, accumulated more radiocesium (Fig. 5.1). The leaf with the highest radiocesium concentration was the uppermost leaf (Fig. 5.1). In contrast, the older leaves contained larger amounts of radiocesium for rice plants harvested in the paddy field (Paddy field B) where brown rice without radiocesium contamination $(<4 \mathrm{~Bq} /$ $\mathrm{kg}$ ) was produced (Fig. 5.1). Given that the soil K concentration in Paddy-field A was low, radiocesium accumulation in the younger parts could be considered to be triggered by $\mathrm{K}$ deficiency. There is frequent $\mathrm{K}$ movement between plant parts. When the plant encounters $\mathrm{K}$ shortage, $\mathrm{K}$ can be translocated from the older tissues to the younger tissues to maintain growth. These $\mathrm{K}$ movements inside the plant could be assumed to be mimicked by Cs; thus, Cs as well as K might accumulate in younger tissues in response to $\mathrm{K}$ deficiency. To produce rice with the least radiocesium content in paddy fields, it is important to understand the radiocesium distribution in rice plants and to distinguish the influencing factors. Therefore, apart from environmental factors, we investigated the physiological effect of K supply on Cs uptake and transport in rice plants using ${ }^{137} \mathrm{Cs}$.

\subsection{Effect of K Concentration in Nutrient Solution on Cs Distribution in Rice Plants}

To analyze the effect of K supply on ${ }^{137} \mathrm{Cs}$ behavior, we compared ${ }^{137} \mathrm{Cs}$ distribution in rice plants grown with or without $\mathrm{K}$. Rice seedlings (Oryza sativa L. Nipponbare) were grown in half-strength Kimura B nutrient solution for 

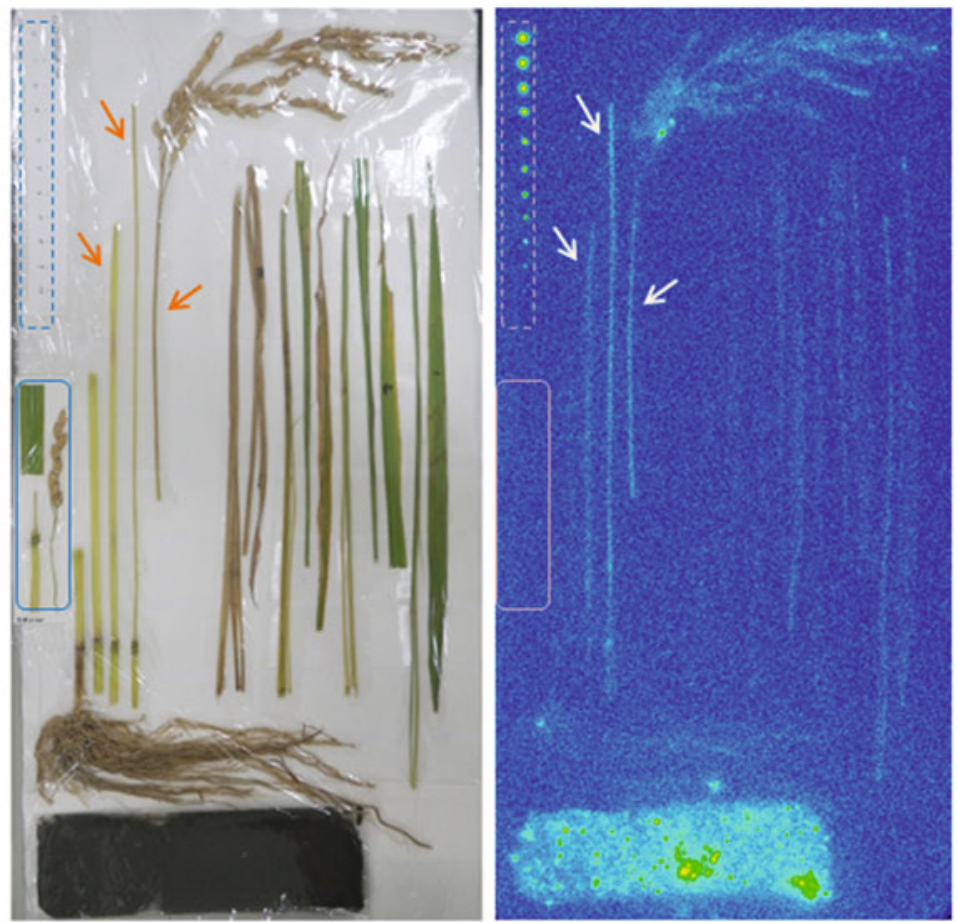

Concentration of ${ }^{137} \mathrm{Cs}$ in the leaf $(\mathrm{Bq} / \mathrm{kg}$ D.W.) Paddy-field A

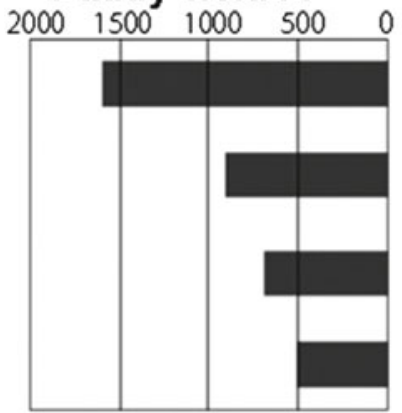

Paddy-field B

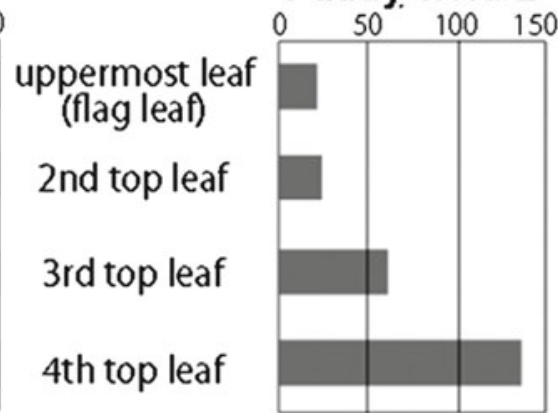

Fig. 5.1 Radiocesium distribution in rice plants harvested in Fukushima in 2011. The upper picture shows the rice plant harvested in paddy-field $\mathrm{A}$ where the highly contaminated rice grain (approximately $500 \mathrm{~Bq} / \mathrm{kg}$ ) was produced. The rice plant was separated into organs and placed with clods of paddy-soil and some reference samples (surrounded with frames). Radioactivity was detected using an imaging plate (BAS IP MS, FujiFilm) and was described with a false color. Arrows indicate the internodes. The bottom graph shows the concentration of ${ }^{137} \mathrm{Cs}$ in the leaves of the rice plants harvested from Paddy-field A and B [Modified from the report by Tanoi et al. (2013)] 
3 weeks and then transplanted either to $3 \mathrm{mM} \mathrm{K}$ or K-free nutrient solution containing ${ }^{137} \mathrm{Cs}(9 \mathrm{kBq} / \mathrm{L})$. The $\mathrm{K}$-sufficient and $\mathrm{K}$-deficient rice plants were grown for another 8 weeks until maturity. For cultivation, a plant growth chamber was set at $30^{\circ} \mathrm{C}$ with a daily $12 \mathrm{~h}$ light and $12 \mathrm{~h}$ dark cycle. After harvesting, the rice plants were separated into several parts and the radioactivity of ${ }^{137} \mathrm{Cs}$ in each part was measured to determine the ${ }^{137} \mathrm{Cs}$ distribution. The $\mathrm{K}$-deficient rice contained nearly 3-times the amount of ${ }^{137} \mathrm{Cs}$ compared with the K-sufficient rice. As presented in Fig. 5.2, it was clear that the K-sufficient rice accumulated ${ }^{137} \mathrm{Cs}$ in the older leaves, whereas the K-deficient rice contained a large amount of ${ }^{137} \mathrm{Cs}$ in the ear and the culm, followed by the upper leaves. Therefore, the distribution of ${ }^{137} \mathrm{Cs}$ in the K-deficient rice (Fig. 5.2) was similar to the radiocesium distribution found in the rice grown in Paddy-field A (Fig. 5.1). In K-deficient rice, the ${ }^{137} \mathrm{Cs}$ accumulated in the ear accounted for more than $25 \%$ of ${ }^{137} \mathrm{Cs}$ found in the shoots, whereas it was less than $10 \%$ in the K-sufficient rice (Fig. 5.2). As a result, $\mathrm{K}$ concentration in the culture solution was shown to impact significantly on Cs distribution within a rice plant.

\subsection{Cation Concentration in K-Sufficient and K-Deficient Rice Plants}

Does $\mathrm{K}$ concentration in solution alter the Cs distribution specifically? This question is important for considering the mechanism regulating $\mathrm{Cs}$ transport inside rice plants. Therefore, we investigated the distribution of sodium $(\mathrm{Na})$, magnesium $(\mathrm{Mg})$, calcium (Ca), as well as $\mathrm{K}$ and ${ }^{137} \mathrm{Cs}$ in $\mathrm{K}$-sufficient and $\mathrm{K}$-deficient rice plants (Fig. 5.3). The concentration of $\mathrm{K}$ in the leaves was higher than in the brown rice when $\mathrm{K}$ was sufficient, which was the reversed response to K-starvation. Interestingly, this alteration was also observed for ${ }^{137} \mathrm{Cs}$ concentrations. $\mathrm{K}$ concentration in the sink organs, such as brown rice, husk, and culm, was not altered by $\mathrm{K}$ deficiency and the order of concentration was brown rice $<$ husk $<$ culm in both $\mathrm{K}$-sufficient and K-deficient rice plants (Fig. 5.3). K was found to be actively transported from the leaves to the reproductive organs to maintain their $\mathrm{K}$ concentration, even if $\mathrm{K}$ was not supplied. The concentration of ${ }^{137} \mathrm{Cs}$ was in the order of brown rice $<$ husk $<$ culm in both K-sufficient and K-deficient rice plants, which was very similar to the order of $\mathrm{K}$ concentration, and the ${ }^{137} \mathrm{Cs}$ concentration in these reproductive organs co-increased in response to K shortage (Fig. 5.3). Less drastically, $\mathrm{K}$-starvation was shown to cause an increase in $\mathrm{Mg}$ concentration and a decrease in $\mathrm{Ca}$ concentration, although the distribution of $\mathrm{Mg}$ and $\mathrm{Ca}$ among organs was not largely modified (Fig. 5.3). On the other hand, Na accumulation in the leaves was promoted drastically under K deficiency. Previous reports suggested that the additional $\mathrm{Na}$ accumulated in the $\mathrm{K}$ deficient leaves could compensate for some function of $\mathrm{K}$, and this could be one reason why $\mathrm{Na}$ absorption was activated under $\mathrm{K}$ deficiency (Rodriguez-Navarro 2000). However, unlike $\mathrm{K}$ and ${ }^{137} \mathrm{Cs}$, $\mathrm{Na}$ 


\section{K-sufficient rice}

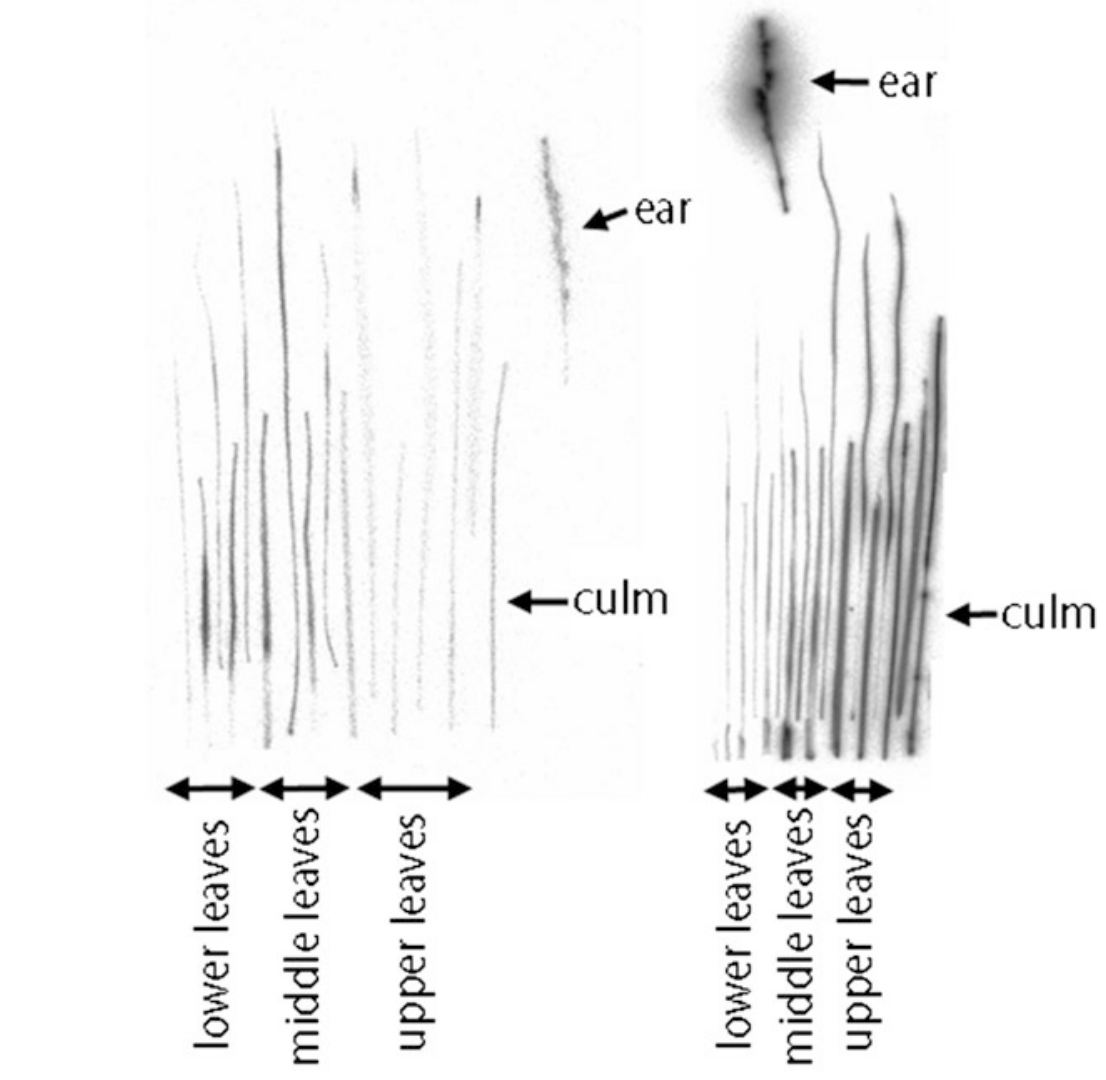

\section{K-deficient rice}
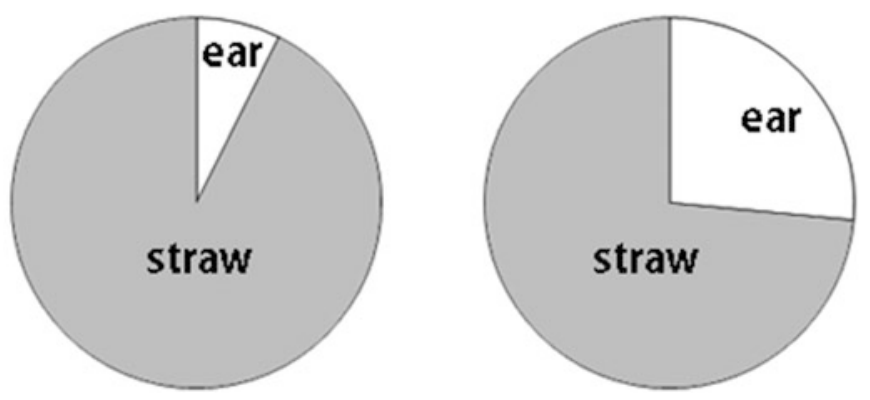

Fig. 5.2 The distribution of ${ }^{137} \mathrm{Cs}$ radioactivity among tissues at harvest. Rice seedlings hydroponically grown with $\mathrm{K}$ ( $3 \mathrm{mM}$, K-sufficient) or without $\mathrm{K}(0 \mathrm{mM}$, K-deficient) were harvested and separated into tissues to determine the ${ }^{137} \mathrm{Cs}$ content using an imaging plate. ${ }^{137} \mathrm{Cs}$ of $9 \mathrm{kBq} / \mathrm{L}$ was supplied from 3 weeks after germination until harvest. In the top images, ${ }^{137} \mathrm{Cs}$ radioactivity in each tissue was presented in the gray-scale. In K-deficient rice, upper leaves accumulated larger amounts of ${ }^{137} \mathrm{Cs}$ compared to the lower leaves. The bottom graph presents the distribution of ${ }^{137} \mathrm{Cs}$ between the ear and the straw [Modified from Kobayashi and Nobori (2014)] 

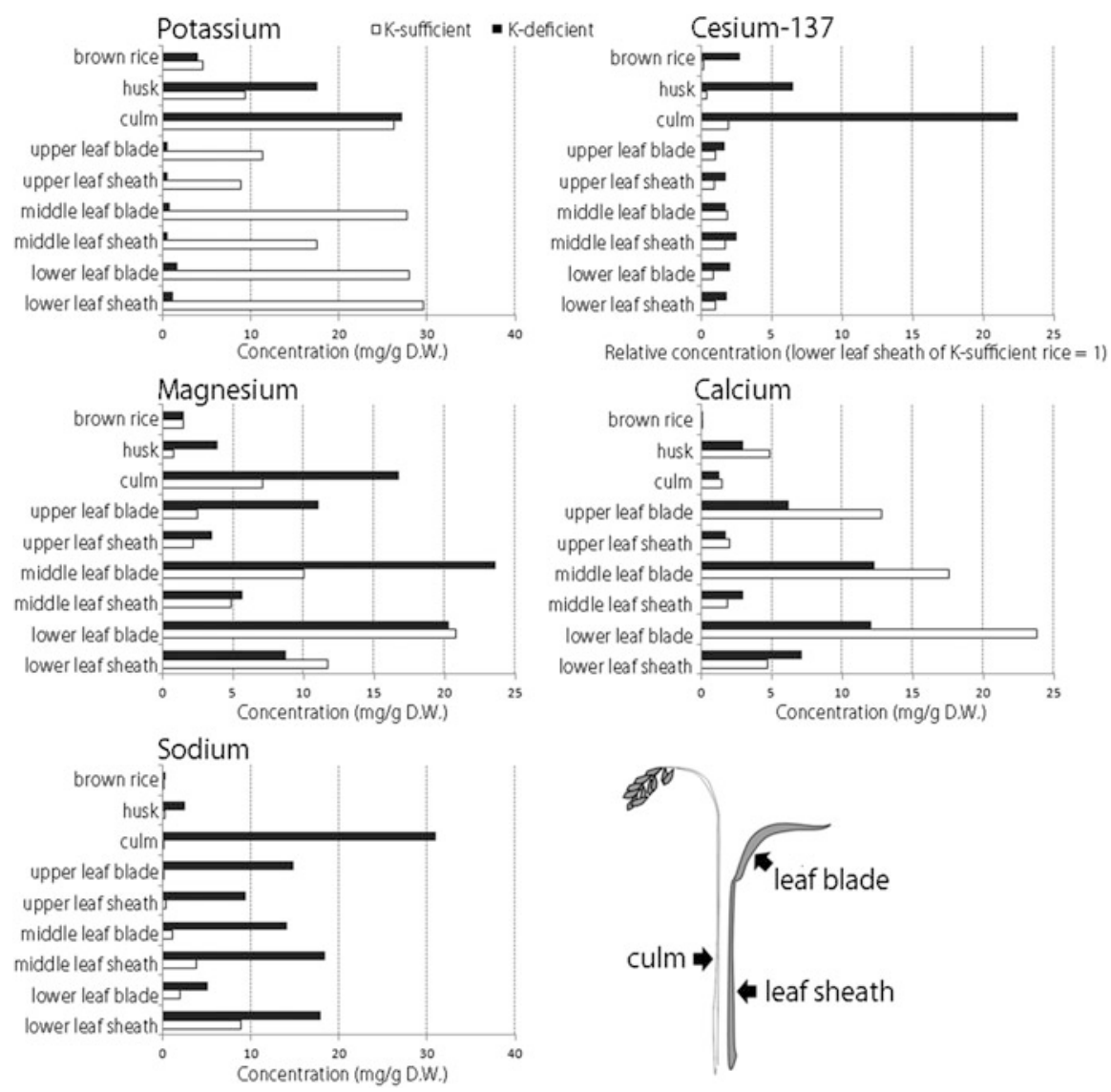

Fig. 5.3 Concentration of $\mathrm{K},{ }^{137} \mathrm{Cs}, \mathrm{Mg}, \mathrm{Ca}$, and $\mathrm{Na}$ in each tissue of $\mathrm{K}$-sufficient (white bar) and $\mathrm{K}$-deficient (black bar) rice plants at harvest. To measure $\mathrm{K}, \mathrm{Mg}, \mathrm{Ca}$, and $\mathrm{Na}$, the tissues were digested with nitric acid and analyzed using ICP-OES (Optima 7300, PerkinElmer). The concentration of ${ }^{137} \mathrm{Cs}$ was determined using gamma counting [Modified from Kobayashi and Nobori (2014)]

concentration in the brown rice and husk remained lower than that in the leaves. These observations indicate that the mechanism regulating $\mathrm{Cs}$ allocation in rice plants is closely related to the $\mathrm{K}$ transport mechanism.

\subsection{The Period for Cs Uptake}

Given the effect of $\mathrm{K}$ supply on the reduction of Cs uptake into the root and Cs transport in brown rice plants, the application of $\mathrm{K}$ fertilizer in paddy fields is suggested as an effective measure to reduce the radiocesium content in rice. 
Fig. 5.4 The ${ }^{137} \mathrm{Cs}$ content in ears of K-sufficient and $\mathrm{K}$-deficient rice at harvest and the period of ${ }^{137} \mathrm{Cs}$ absorption. K-deficient rice accumulated 10-times more ${ }^{137} \mathrm{Cs}$ in the ear as K-sufficient rice. Over $90 \%$ of the ${ }^{137} \mathrm{Cs}$ in the ear at harvest, was absorbed before heading, and was probably relocated from the leaves to the ear as the ear matured, regardless of the $\mathrm{K}$ condition [Modified from Kobayashi and Nobori (2014)]

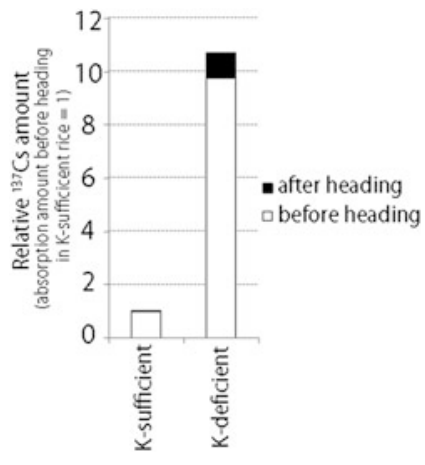

Subsequently, to develop a practical $\mathrm{K}$ fertilization scheme, it is important to determine the developmental period when rice plants absorb Cs and transport it toward the grain. Therefore, we compared the ${ }^{137} \mathrm{Cs}$ amount in the ear of rice plants supplied with ${ }^{137} \mathrm{Cs}$ after the third week until harvest with that of rice plants to which ${ }^{137} \mathrm{Cs}$ was supplied only after heading. The disparity between them could correspond to the ${ }^{137} \mathrm{Cs}$ amount absorbed before heading. The results showed that over $90 \%$ of ${ }^{137} \mathrm{Cs}$ accumulated in the ear at harvest was absorbed before heading (Fig. 5.4). This means that most of the ${ }^{137} \mathrm{Cs}$ found in the ear was once stored in other parts, such as the leaves, and then relocated to the ear after heading. Furthermore, the amount of ${ }^{137} \mathrm{Cs}$ relocated to the ear after heading was increased nearly tenfold in response to $\mathrm{K}$ deficiency. Considering that the relocation of $\mathrm{Cs}$ from the leaves to the ear can accompany $\mathrm{K}$ movement, which could be modified depending on the level of $\mathrm{K}$ supply, it is possible that $\mathrm{K}$ supplement after heading can reduce Cs transport toward the ear. Thus, we tested this idea by transplanting K-deficient rice seedlings to the $3 \mathrm{mM} \mathrm{K}$ medium without ${ }^{137} \mathrm{Cs}$ at heading.

\subsection{Evaluation of the Effect of Additional K Fertilization on Cs Movement}

At harvest, the proportion of ${ }^{137} \mathrm{Cs}$ content in the ear to the total ${ }^{137} \mathrm{Cs}$ absorbed before heading (the ear fraction) in the $\mathrm{K}$-sufficient rice and $\mathrm{K}$-deficient rice was $17.3 \%$ and $27.8 \%$, respectively (Table 5.1). Then, the ear fraction in rice plants to which $\mathrm{K}$ was supplied after heading was $25.0 \%$ (Table 5.1). These results imply that $\mathrm{K}$ fertilization after heading has only a minor effect on Cs relocation. Meanwhile, transition to the K-rich condition after heading is assumed to be effective for reducing Cs uptake in roots. However, such a reduction is expected to have a limited impact on Cs content in brown rice because the amount of Cs absorbed 
Table 5.1 Influence of $\mathrm{K}$ supply on ${ }^{137} \mathrm{Cs}$ transport to the ear after heading

\begin{tabular}{l|l|l}
\hline K- condition & \multirow{2}{*}{ Distribution to the ear (\%) } \\
\hline Before heading & After heading & 17.3 \\
\hline Sufficient & Sufficient & 27.8 \\
\hline Deficient & Deficient & 25.0 \\
\hline Deficient & Sufficient & \\
\hline${ }^{137}$ Cs was added to the solution medium only before heading, and its distribution at harvest was \\
determined. Rice plants grown under K sufficient conditions both before and after heading \\
accumulated 17.3\% of ${ }^{137} \mathrm{Cs}$ in the ear. The percentage increased to 27.8 \% in rice plants \\
grown under K deficient conditions. Then, rice plants grown under K-deficient conditions until \\
heading and then transplanted into K-sufficient solution relocated $25.0 \%$ of ${ }^{137}$ Cs to the ear \\
[Modified from Kobayashi and Nobori (2014)]
\end{tabular}

after heading accounts for less than $10 \%$ of the Cs content in the ear part at harvest (Fig. 5.4). Therefore, in consideration of plant physiology, the importance of a base-fertilizer, rather than additional fertilization, was demonstrated to reduce radiocesium contamination in rice.

\subsection{Conclusion and Future Perspectives}

The supply of $\mathrm{K}$ to rice plants decreased the Cs content in brown rice as a consequence of reduction of both Cs uptake by the root and Cs transport toward the edible part. Application of $\mathrm{K}$ fertilizer to some paddy fields in Fukushima apparently reduced the radiocesium concentration in brown rice, and the ear fraction of radiocesium content was decreased by half (unpublished data). Finally, in the autumn of 2014, all the brown rice commercially produced passed the test for sale. To keep the radiocesium contamination low, it could be important to maintain an appropriate $\mathrm{K}$ condition in rice plants. Regarding the determination of the $\mathrm{K}$ condition in plants, analyzing the radiocesium distribution among tissues, as well as the $\mathrm{K}$ concentration in the soil, is thought to improve the accuracy. If radiocesium concentration is lower in younger tissues than older tissues, the plant is considered to have enough $\mathrm{K}$ and thus additional $\mathrm{K}$ fertilization would have only minor benefits through the absorption competition as previously reported (Kobayashi et al. 2015). In these cases, some other factors influencing radiocesium behavior should be evaluated to reduce the radiocesium contamination.

In this study, we focused on the similarity of behavior between $\mathrm{K}^{+}$and $\mathrm{Cs}^{+}$. However, their behavior is close but not the same. The ratio of $\mathrm{K}$ uptake rate to $\mathrm{Cs}$ uptake rate was found to be 7-11 times higher than the ratio of $\mathrm{K}$ concentration to Cs concentration in the culture medium, indicating that the root absorbs $\mathrm{K}$ selectively over Cs (Kobayashi et al. 2015). In addition, $\mathrm{K}$ was shown to be selectively relocated to the rice grain over Cs (Nobori et al. 2014). Characterization of the molecular machinery regulating the movement of $\mathrm{K}$ and Cs can further assist our 
understanding of Cs behavior in plants and assist breeding of low-Cs cultivars, which can assure the stable production of agricultural products in the future.

Open Access This chapter is distributed under the terms of the Creative Commons Attribution Noncommercial License, which permits any noncommercial use, distribution, and reproduction in any medium, provided the original author(s) and source are credited.

\section{References}

Kobayashi NI, Nobori T (2014) New Food Ind 56:1-7 (in Japanese)

Kobayashi NI, Sugita R, Nobori T, Tanoi K, Nakanishi TM (2015, accepted) Tracer experiment using ${ }^{42} \mathrm{~K}^{+}$and ${ }^{137} \mathrm{Cs}^{+}$revealed the different transport rates of potassium and caesium within rice roots. Funct Plant Biol.

Nobori T, Kobayashi NI, Tanoi K, Nakanishi TM (2014) Effects of potassium in reducing the radiocesium translocation to grain in rice. Soil Sci Plant Nutr 60:772-781

Qi Z, Hampton CR, Shin R, Barkla BJ, White PJ, Schachtman DP (2008) The high affinity $\mathrm{K}^{+}$ transporter AtHAK5 plays a physiological role in planta at very low $\mathrm{K}^{+}$concentrations and provides a caesium uptake pathway in Arabidopsis. J Exp Bot 59:595-607

Robison WL, Brown PH, Stone EL, Hamilton TF, Conrado CL, Kehl S (2009) Distribution and ratios of ${ }^{137} \mathrm{Cs}$ and $\mathrm{K}$ in control and $\mathrm{K}$-treated coconut trees at Bikini Island where nuclear test fallout occurred: effects and implications. J Environ Radioact 100:76-83

Rodriguez-Navarro A (2000) Potassium transport in fungi and plants. Biochim Biophys Acta 1469:1-30

Tanoi K, Kobayashi NI, Ono Y, Fujimura S, Nakanishi TM (2013) Radiocesium distribution in rice plants grown in the contaminated soil in Fukushima prefecture in 2011. Radioisotopes 62:25-29 (in Japanese)

Zhi Y-G, Shaw G, Nisbet AF, Wilkins BT (2002) Effect of external potassium supply and plant age on the uptake of radiocesium $\left({ }^{137} \mathrm{Cs}\right.$ ) by broad bean (Vicia faba): interpretation of results from a large-scale hydroponic study. Environ Exp Bot 47:173-187 